\title{
Outcomes and lessons from the PROactive study
}

\author{
André J. Scheen \\ Division of Diabetes, Nutrition and Metabolic Disorders, and Division of Clinical Pharmacology, Department of Medicine, CHU Sart \\ Tilman, University of Liège, Liège, Belgium
}

\begin{abstract}
Beyond improvement of glucose control, thiazolidinediones exert pleiotropic effects, which may contribute to some cardiovascular protection. PROactive ("PROspective pioglitAzone Clinical Trial In macroVascular Events") has provided valuable, although controversial, information on the impact of pioglitazone on cardiovascular outcomes in a high-risk population of patients with type 2 diabetes and established macrovascular disease. Since 2005, there has been much debate on the relative value of the statistically non-significant $10 \%$ reduction in the quite challenging primary composite endpoint (combining cardiovascular disease-driven and procedural events in all vascular beds) versus the statistically significant $16 \%$ decrease in the more robust and conventional main secondary endpoint (all-cause mortality, myocardial infarction, and stroke) observed with pioglitazone. Revisiting PROactive deserves much interest following the report of inconclusive results on cardiovascular efficacy and safety of rosiglitazone in RECORD, the withdrawal (limitation) of rosiglitazone because of cardiovascular safety concern, the recent publication of a statement positioning pioglitazone in type 2 diabetes and the near availability of cheaper generics of pioglitazone. Although subanalyses may have more limited value from a statistical viewpoint, they nonetheless can provide valuable information on the drug efficacy/safety profile and clinical insights into which patients might benefit most (in terms of cardiovascular outcomes) from pioglitazone therapy.
\end{abstract}

Keywords : Cardiovascular outcome ; Heart failure ; Glucose control ; Pioglitazone ; PROactive ; Thiazolidionedione; Type 2 diabetes mellitus

\section{Introduction}

Type 2 diabetes mellitus (T2DM) is associated with an increased risk of cardiovascular (CV) events that carry a poor prognosis. Majority of patients with T2DM are insulin resistant and have associated metabolic abnormalities that are also significant CV risk factors [1]. Thiazolidinediones (TZDs), acting as agonists of peroxisome proliferator-activated receptor gamma (PPAR gamma), are currently the only available oral antihyperglycaemic medications that reduce insulin resistance [2]. In addition to lowering blood glucose, TZDs have been shown to affect and reduce many surrogate markers of CV risk in patients with T2DM [3-6]. Especially, pioglitazone has the ability to address key features of the metabolic syndrome $[5,7,8]$. Beyond favourable effects on glucose metabolism and glucose control, pioglitazone has indeed positive effects on lipid metabolism, blood pressure, endothelial function, markers of silent inflammation (C-reactive protein) and adiponectin levels. All these observations paved the way to the initiation of large prospective placebo-controlled trials assessing the efficacy of TZDs on CV outcomes in patients with T2DM.

PROactive ("PROspective pioglitAzone Clinical Trial In macroVascular Events") was the first CV outcomes study with a TZD. It was a prospective, randomized controlled trial in 5238 patients with T2DM who had evidence of macro-vascular disease $[9,10]$. Patients recruited were assigned to oral pioglitazone titrated from 15 $\mathrm{mg}$ to $45 \mathrm{mg}(n=2605)$ or matching placebo $(n=2633)$, to be taken in addition to their glucose-lowering drugs and other medications [10]. The end of the trial was event-driven and the average time of observation was 34.5 months. The aim of PROactive was to ascertain whether pioglitazone reduces macrovascular morbidity and mortality in high-risk patients with T2DM. Pioglitazone was associated with a numerical (not statistically significant) reduction in a quite complex primary composite endpoint that involved cerebral, cardiac, and peripheral vessels. Interestingly enough, piogliazone was associated with a significant reduction in a more limited, but also stronger and more conventional, so-called main secondary endpoint (composite of all-cause mortality, non-fatal myocardial infarction or MI, and stroke) [10]. 
Immediately after the publication of PROactive in 2005, the interpretation of the available data was controversial [11-14]. Indeed, CV outcome results raised much discussion [11-13] and even suspicion [14]. A few years later, controversy still persists as most people consider that the balance of pioglitazone is positive [15-19] whereas other concludes that there is no prove that pioglitazone is cardioprotective [20]. The conclusion of a Cochrane Database Systematic Review was that the results of PROactive have to be regarded as hypothesis-generating and need confirmation [20].

Another controlled trial was published a few years later, which assessed the CV efficacy and safety of a TZD, RECORD ("Rosiglitazone Evaluated for Cardiovascular Outcomes in Oral Agent Combination Therapy for Type 2 Diabetes"). It was the only prospective randomized trial designed to specifically evaluate CV outcomes with rosiglitazone. This trial was of major interest after the publication of a meta-analysis of 42 trials showing that rosiglitazone was associated with a significant increase in the risk of MI and with an increase in the risk of death from CV causes that had borderline significance [21]. The data from RECORD were inconclusive about any possible harmful effect on MI, but rosiglitazone did not increase the risk of overall CV morbidity or mortality compared with standard glucose-lowering drugs [22]. However, the results were limited because of issues with study design and event adjudication. Therefore, the CV safety concern of rosiglitazone persisted and was even reinforced by observational data [23]. Consequently, the use of rosiglitazone was not recommended anymore in guidelines published in 2009 [24] and this TZD was withdrawn from the market in many countries (all European countries for instance) in 2010 while its clinical use was markedly limited in the United States of America [25].

A first critical appraisal of PROactive, comprising an extensive safety data set, as well as new insights into the impact of pioglitazone in different patient subpopulations, was published in 2008 [26]. An overview of all the key safety and tolerability characteristics associated with pioglitazone therapy in PROactive was published one year later [27]. However, there are at least three main reasons for revisiting PROactive. First, since that time, new results resulting from specific post hoc analyses have been available. Second, the withdrawal of rosiglitazone raises much suspicion on the pharmacological class of TZDs in general, especially regarding its $\mathrm{CV}$ safety in high-risk patients [17,28]. Third, a recent position statement of the American Diabetes Association (ADA) and the European Association for the Study of Diabetes (EASD) published an updated algorithm for the initiation and adjustment of therapy for the management of hyperglycaemia in T2DM [29]. According to this position statement, "pioglitazone appeared to have a modest benefit on cardiovascular events as a secondary outcome in one large trial involving patients with overt macrovascular disease". In the proposed algorithm, pioglitazone can be considered as a valuable alternative as monotherapy if metformin cannot be used (not tolerated or contraindicated), as dual combination therapy if monotherapy with metformin alone does not achieve/maintain a glycated haemoglobin $\left(\mathrm{HbA}_{1 \mathrm{c}}\right)$ target or as triple combination therapy provided that oral agents with complementary mechanisms of action are used. Still now, the most relevant evidence-based data supporting the use of pioglitazone in T2DM can be found in PROactive. The aim of the present review paper is to revisit PROactive data by critically analysing various clinical outcomes and recent results in order to help physicians in their decision to use or not use pioglitazone for the management of T2DM.

\section{Cardiovascular outcomes}

\subsection{Primary endpoint}

The investigators in PROactive chose a challenging primary composite endpoint that included events in multiple vascular beds (cerebral, cardiac, and peripheral), as well as both disease-related and procedural endpoints. Indeed, the primary endpoint was the composite of all-cause mortality, non fatal MI (including silent MI), stroke, acute coronary syndrome (ACS), endovascular or surgical intervention in the coronary or leg arteries, and amputation above the ankle. In an intention to treat analysis, 514 of 2605 patients in the pioglitazone group and 572 of 2633 patients in the placebo group had at least one event in the primary composite endpoint (hazard ratio or HR $=0.90,95 \%$ CI $0.80-1.02, P=0.095)$ (Table 1$)$. Thus, the between-treatment difference did not reach the level of statistical significance. However, this primary composite endpoint is rather heterogeneous as it comprises both cardiac and peripheral CV endpoints. When the individual components of the primarily endpoints are analysed separately, it appears that cardiac and cerebrovascular endpoints are positively influenced by pioglitazone, whereas endpoints concerning peripheral artery disease (PAD) are negatively impacted (see below). 
Table 1 - Cardiovascular outcomes in various subgroups of the PROactive trial. Results are given as hazard ratios (HR) with 95\% confidence intervals in patients receiving pioglitazone (Pio) vs patients receiving placebo (Pbo). NA, not available. See text for description of primary and main secondary endpoints.

\begin{tabular}{|c|c|c|c|c|c|c|}
\hline Groups of patients & N Pio vs Pbo & $\begin{array}{l}\text { Primary composite } \\
\text { endpoint }\end{array}$ & $\begin{array}{l}\text { Main secondary } \\
\text { endpoint }\end{array}$ & All-cause mortality & $\begin{array}{l}\text { Specific endpoint } \\
\text { (see footnote) }\end{array}$ & \\
\hline Overall & 2605 vs 2633 & $\begin{array}{l}\mathrm{HR}=0.90,0.80-1.02 \\
P=0.095\end{array}$ & $\begin{array}{l}\mathrm{HR}=0.84,0.72-0.98 \\
P=0.027\end{array}$ & $\begin{array}{l}\mathrm{HR}=0.96,0.78-1.18 \\
P=0.68\end{array}$ & $\begin{array}{l}\mathrm{HR}=0.82,0.70-0.97 \\
P=0.020^{\mathrm{a}}\end{array}$ & \\
\hline $\begin{array}{l}\text { Previous myocardial } \\
\text { infarct }\end{array}$ & 1230 vs 1215 & $\begin{array}{l}\mathrm{HR}=0.88,0.75-1.04 \\
P=0.135\end{array}$ & $\begin{array}{l}\mathrm{HR}=0.81,0.65-1.01 \\
P=0.058\end{array}$ & $\begin{array}{l}\mathrm{HR}=0.85,0.63-1.15 \\
P=0.2873\end{array}$ & $\begin{array}{l}\mathrm{HR}=0.72,0.52-0.99 \\
P=0.045^{\mathrm{b}}\end{array}$ & Erd \\
\hline Previous stroke & 486 vs 498 & $\begin{array}{l}\mathrm{HR}=0.78,0.60-1.02 \\
P=0.067\end{array}$ & $\begin{array}{l}\mathrm{HR}=0.78,0.58-1.06 \\
P=0.110\end{array}$ & $\begin{array}{l}\mathrm{HR}=0.96,0.64-1.44 \\
P=0.843\end{array}$ & $\begin{array}{l}\mathrm{HR}=0.53,0.34-0.85 \\
P=0.0085^{\mathrm{c}}\end{array}$ & \\
\hline $\begin{array}{l}\text { Presence of peripheral } \\
\text { artery disease }\end{array}$ & 619 vs 655 & $\begin{array}{l}\mathrm{HR}=1.09,0.88,1.34 \\
P=0.4344\end{array}$ & $\begin{array}{l}\mathrm{HR}=0.88,0.67,1.16 \\
P=0.3738\end{array}$ & $\begin{array}{l}\mathrm{HR}=1.02,0.73,1.43 ; \\
P=0.9145\end{array}$ & $\begin{array}{l}\mathrm{HR}=1.58,0.81,3.12 \\
P=0.1820^{\mathrm{d}}\end{array}$ & Dorm \\
\hline $\begin{array}{l}\text { Absence of peripheral } \\
\text { artery disease }\end{array}$ & 1986 vs 1978 & $\begin{array}{l}\mathrm{HR}=0.84,0.72,0.97 \\
P=0.0160\end{array}$ & $\begin{array}{l}\mathrm{HR}=0.83,0.69,1.00 \\
P=0.0453\end{array}$ & $\begin{array}{l}\mathrm{HR}=0.93,0.72,1.21 \\
P=0.6094\end{array}$ & $\begin{array}{l}\mathrm{HR}=0.41,0.15,1.17 \\
P=0.0954^{\mathrm{d}}\end{array}$ & Dorm \\
\hline $\begin{array}{l}\text { Presence of chronic } \\
\text { kidney disease }\end{array}$ & 274 vs 323 & $\begin{array}{l}\mathrm{HR}=0.75,0.55-1.03 \\
P=\text { NA }\end{array}$ & $\begin{array}{l}\mathrm{HR}=0.66,0.45-0.98 \\
P=\text { NA }\end{array}$ & $\begin{array}{l}\mathrm{HR}=0.75,0.55-1.03 \\
P=\mathrm{NA}^{\mathrm{e}}\end{array}$ & NA & \\
\hline $\begin{array}{l}\text { Absence of chronic } \\
\text { kidney disease }\end{array}$ & 2292 vs 2265 & $\begin{array}{l}\mathrm{HR}=0.94,0.83-1.07 \\
P=\mathrm{NA}\end{array}$ & $\begin{array}{l}\mathrm{HR}=0.89,0.75-1.05 \\
P=\mathrm{NA}\end{array}$ & $\begin{array}{l}\mathrm{HR}=1.09,0.87-1.38 \\
P=\text { NA }\end{array}$ & NA & Schr \\
\hline $\begin{array}{l}\text { Patients on insulin at } \\
\text { baseline }\end{array}$ & 864 vs 896 & $\begin{array}{l}\mathrm{HR}=0.86,0.71-1.04 \\
P=0.1198\end{array}$ & $\begin{array}{l}\mathrm{HR}=0.85,0.67-1.08 \\
P=0.1831\end{array}$ & NA & NA & Chark \\
\hline $\begin{array}{l}\text { Patients developing } \\
\text { serious heart failure }\end{array}$ & 149 vs 108 & $\begin{array}{l}\mathrm{HR}=0.72,0.51-1.01 \\
P=0.059\end{array}$ & $\begin{array}{l}\mathrm{HR}=0.64,0.44-0.95 \\
P=0.025\end{array}$ & $\begin{array}{l}\mathrm{HR}=0.71,0.45-1.11 \\
P=0.14\end{array}$ & NA & Better \\
\hline $\begin{array}{l}{ }^{\mathrm{a}} \mathrm{Car} \\
{ }^{\mathrm{b}} \mathrm{Fat} \\
{ }^{\mathrm{c}} \mathrm{Fat} \\
{ }^{\mathrm{d}} \mathrm{Am}\end{array}$ & ion. & $\begin{array}{l}\text { nonfatal myocardial infarc } \\
\text { cluding silent MI). }\end{array}$ & tion (MI) or nonfatal strok & & & \\
\hline
\end{tabular}

\subsection{Main secondary endpoint}

A so-called main secondary endpoint was defined by the authors of PROactive as the composite of all-cause mortality, non-fatal MI, and stroke [10]. Thereby, this main secondary endpoint only included disease endpoints and not procedural endpoints [11]. A total of 301 patients in the pioglitazone group and 358 in the placebo group reached this endpoint $(\mathrm{HR}=0.84,95 \%$ CI $0.72-0.98, P=0.027)$ (Table 1) [10]. Thus, the between-treatment difference became statistically significant. The relative risk of all-cause death, MI, and stroke for pioglitazone versus placebo was similar regardless of the baseline use of nitrates, blockers of the renin-angiotensin system, or insulin, with HR ranging from 0.81 to 0.87 [30].

Strongly divergent interpretations regarding the valid use and the clinical significance of this main secondary endpoint have been published after the original publication of PROactive.

The relative value of the primary and main secondary endpoints in PROactive has been already discussed [26]. For some authors ("supporters"), if procedure-related endpoints (coronary and especially leg revascularization) are excluded, the efficacy of pioglitazone in the prevention of all-cause mortality, non-fatal MI and stroke, in high risk patients with T2DM, is clearly shown by the study [26]. For other authors ("opponents"), in any case, all of the argument and discussion about the importance of the main secondary endpoint cannot negate the fact that the primary endpoint failed to reach significance. For clinical trialists, secondary endpoinds should only be considered meaningful when the primary endpoint is positive. Otherwise, in the face of a negative primary endpoint, secondary endpoints should only be considered exploratory or hypothesis generating. If so, the correct statistical interpretation of the study would be that it is negative [14]. It is presumably the reason why the results of PROactive have to be regarded as hypothesis-generating and need confirmation according to the conclusion of a Cochrane Database Systematic Review [20].

Interestingly, the same composite endpoint was evaluated in a meta-analysis of 19 trials randomized trials evaluating piogliazone in a total of 16,390 patients with T2DM. Study drug treatment duration ranged from 4 months to 3.5 years. Death, MI, or stroke occurred in 375 of 8554 patients (4.4\%) receiving pioglitazone and 450 of 7836 patients $(5.7 \%)$ receiving control therapy (HR, 0.82, 95\% CI 0.72-0.94, $P=0.005)$. Progressive separation of time-to-event curves became apparent after approximately 1 year of therapy. Individual 
components of the primary endpoint were all reduced by a similar magnitude with pioglitazone treatment, with HRs ranging from 0.80 to 0.92 . The magnitude of the favourable effect of pioglitazone on ischemic events was homogeneous across trials of different durations, for different comparators, and for patients with or without established vascular disease [31].

\subsection{MACE as a composite endpoint}

Composite endpoints of major adverse CV events (MACEs) are standard measures for comparing treatment in large CV outcome studies. An analysis from PROactive evaluated the effects of pioglitazone on the prespecified MACE endpoint of CV death, nonfatal MI, or nonfatal stroke and on 6 post hoc MACE composites (various combinations of all-cause, CV, or cardiac mortality; plus nonfatal MI; plus nonfatal stroke; and/ or ACS) in patients with T2DM [32]. At final visit, 257 (9.9\%) pioglitazone-treated and 313 (11.9\%) placebo-treated patients had a first event that contributed to the principal MACE endpoint (CV death, nonfatal MI, or nonfatal stroke $)(\mathrm{HR}=0.82,95 \%$ CI $0.70-0.97, P=0.0201)$. Such MACE endpoint slightly differs from the main secondary endpoint in the original paper of PROactive (see above) by using CV deaths instead of all-cause mortality. There were statistically significant differences in favour of pioglitazone in 5 of the other MACE endpoints $(P<0.05)$ and a trend to benefit in the sixth $(P=0.052)$, with HR of 0.79-0.83. Thus, in patients with advanced T2DM at high risk for $\mathrm{CV}$ events, pioglitazone treatment resulted in significant risk reductions in MACE composite endpoints.

The results of PROactive have been supported by two subsequent studies (CHICAGO and PERISCOPE) examining the impact of pioglitazone on important surrogates of atherosclerosis, namely carotid intima/medial thickness and coronary atheroma volume as delineated with intravascular ultrasound [33].

Table 2 compares various clinical endpoints in the two large prospective randomized clinical trials with CV outcomes assessing the efficacy and safety of TZDs in patients with T2DM: PROactive comparing pioglitazone with placebo, on the one hand, and RECORD comparing rosiglitazone versus an active comparator (metformin or sulfonylurea), on the other hand. A significant reduction in a composite endpoint comprising CV deaths plus non fatal MI plus non fatal stroke was observed in PROactive (HR $=0.82,95 \%$ CI $0.70-0.97$ ) but not in RECORD $(\mathrm{HR}=0.93,95 \% \mathrm{CI}$ 0.74-1.15). A trend for a lower incidence of MI was observed with pioglitazone in PROactive whereas a trend for a higher incidence of MI with rosiglitazone was observed in RECORD. No differences were observed in all-cause deaths or CV deaths (Table 2). However, caution is required in absence of head-to-head comparison because of potential confounding factors such as differences between PROactive and RECORD in patient CV risk profile, baseline therapy, drug used as comparator and duration of follow-up.

Table 2 - Comparison of several cardiovascular (CV) outcomes in PROactive with pioglitazone vs placebo and in RECORD with rosiglitazone vs metformin (MET) or sulfonylurea (SU). Results are given as number of events, hazard ratios (HR) and 95\% confidence intervals (CI). CHF, congestive heart failure. NA, not available.

\begin{tabular}{lcccccc}
\hline Endpoints & \multicolumn{3}{c}{$\begin{array}{c}\text { PROACTIVE } \\
\text { BASELINE: any therapy } \\
\text { Follow up =2.8 years }\end{array}$} & \multicolumn{2}{c}{$\begin{array}{c}\text { RECORD BASELINE: SU or MET Follow up } \\
=5.5 \text { years }\end{array}$} \\
\cline { 2 - 7 } & $\begin{array}{c}\text { Pioglitazone } \\
(n=2605)\end{array}$ & $\begin{array}{c}\text { Placebo } \\
(n=2633)\end{array}$ & HR $(95 \%$ CI $)$ & $\begin{array}{c}\text { Rosiglitazone } \\
(n=2220)\end{array}$ & $\begin{array}{c}\text { SU or MET } \\
(n=2227)\end{array}$ & HR (95\% CI) \\
\hline Composite endpoint $^{\mathrm{a}}$ & 257 & 313 & $0.82(0.70-0.97)$ & 154 & 165 & $0.93(0.74-1.15)$ \\
All-cause deaths & 177 & 186 & $0.96(0.78-1.18)$ & 136 & 157 & $0.86(0.68-1.08)$ \\
CV deaths & 127 & 136 & $0.94(0.74-1.20)$ & 60 & 71 & $0.84(0.59-1.18)$ \\
Myocardial infarction & 119 & 144 & $0.83(0.65-1.06)$ & 64 & 56 & $1.14(0.80-1.63)$ \\
Stroke & 86 & 107 & $0.81(0.61-1.07)$ & 46 & 63 & $0.72(0.49-1.06)$ \\
Serious CHF & 149 & 108 & $1.41(1.10-1.80)$ & 61 & 29 & $2.1(1.35-3.27)$ \\
Fatal CHF & 25 & 22 & $1.15(0.65-2.03)$ & 10 & 2 & $5(\mathrm{NA})$ \\
\hline
\end{tabular}

Data obtained from Dormandy et al. [10], Wilcox et al. [32] and Erdman et al. [38] for PROactive and from Home et al. [22] and Komjada et al. [40], for RECORD.

${ }^{a}$ Cardiovascular mortality plus non fatal MI plus non fatal stroke. 


\subsection{Myocardial infarction}

Of the total cohort from PROactive, the subgroup of patients who had a previous MI (1230 = pioglitazone; 1215 = placebo) was evaluated using prespecified and post hoc analyses [34]. Pioglitazone had a statistically significant beneficial effect on the prespecified endpoint of fatal and nonfatal MI ( $28 \%$ risk reduction [RR]; $P=$ $0.045)$ and ACS (37\% RR; $P=0.035)$. There was a $19 \% \mathrm{RR}$ in the cardiac composite endpoint of nonfatal MI (excluding silent MI), coronary revascularization, ACS, and cardiac death $(P=0.033)$. The difference in the primary endpoint defined in the main PROactive study did not reach significance in the MI population $(12 \% \mathrm{RR}$; $P=0.135$ ) (Table 1). The conclusion was that in high-risk patients with T2DM and previous MI, pioglitazone significantly reduced the occurrence of fatal and nonfatal MI and ACS.

\subsection{Stroke}

A subgroup analysis evaluated the risk of stroke and other CV outcomes in patients with $(n=984)$ and without $(n=4254)$ prior stroke [35]. In patients with previous stroke $(486=$ pioglitazone; $498=$ placebo $)$, there was a trend of benefit with pioglitazone for the primary endpoint of PROactive and for the main secondary endpoint (Table 1). Pioglitazone reduced fatal or nonfatal stroke (HR $=0.53,95 \% \mathrm{CI} 0.34-0.85 ; P=0.0085)$ and $\mathrm{CV}$ death, nonfatal MI, or nonfatal stroke $(\mathrm{HR}=0.72,95 \% \mathrm{CI}=0.52-1.00 ; P=0.0467)$. In patients without prior stroke, no treatment effect was observed for a first stroke. Thus, in this subgroup analysis from PROactive, pioglitazone markedly (almost by half) and significantly reduced the risk of recurrent stroke in high-risk patients with T2DM.

\subsection{Peripheral artery disease}

In the total PROactive population, multivariate analysis showed that the presence of PAD at baseline significantly affected the outcome of the primary $(\mathrm{HR}=1.48,95 \% \mathrm{CI} 1.26-1.72, P<0.0001)$ and main secondary endpoints $(\mathrm{HR}=1.35,95 \% \mathrm{CI}=1.10,1.65 ; P=0.0036)[10]$.

Therefore, CVD outcomes were compared according to the presence of PAD at baseline in a post hoc analysis [36]. Of the 5238 patients in PROactive, 1274 had PAD at baseline $(619=$ pioglitazone; $655=$ placebo). Patients with PAD at baseline showed significantly higher rates of the primary endpoint, main secondary endpoint, allcause mortality (all $P<0.0001)$, and stroke $(P=0.0175)$ than those with no PAD at baseline. The risk of PAD alone was similar to that of MI alone. The presence of PAD increased the risk of all major CVevents. In patients with no PAD at baseline, the event rates of the primary endpoint $(P=0.0160)$, main secondary endpoint $(P=$ $0.0453)$, and acute coronary syndrome $(P=0.0287)$ were significantly lower with pioglitazone than with placebo. For unknown reasons, this beneficial effect of pioglitazone was not seen in patients with PAD at baseline (Table 1). The conclusion was that T2DM patients without PAD at baseline seemed to benefit more from pioglitazone treatment than the overall PROactive population.

\subsection{Congestive heart failure}

Patients with New York Heart Association (NYHA) Class II-IV congestive heart failure (CHF) at screening were excluded from PROactive. Overall during the trial, 6\% (149 of 2065) and 4\% (108 of 2633) of those in the pioglitazone and placebo groups, respectively, were admitted to hospital with CHF; however, mortality rates from CHF did not differ between groups (Table 2) [10]. A post hoc, blinded, independent adjudication of investigator-reported serious CHF events (those requiring hospital admission) dismissed a small number of investigator-reported events and identified several new cases. However, the higher prevalence with pioglitazone than placebo was confirmed (5.5\% vs $4.2 \%$ ) [37]. These data were confirmed in the already mentioned metaanalysis of 19 randomized trials, in which serious CHF was reported in $200(2.3 \%)$ of the 8554 pioglitazonetreated patients and $139(1.8 \%)$ of the 7836 control patients ( $\mathrm{HR}=1.41 ; 95 \% \mathrm{CI} 1.14-1.76, P=0.002)$ [31].

A secondary paper specifically analysed all CHF cases to assess the effects of treatment on morbidity and mortality after reports of serious CHF [38]. A serious adverse event of CHF was defined as CHF that required hospitalization or prolonged a hospitalization stay, was fatal or life threatening, or resulted in persistent significant disability or incapacity. More pioglitazone (5.7\%) than placebo patients $(4.1 \%)$ had a serious CHF event during the PROactive study $(\mathrm{P}=0.007)$. However, mortality due to CHF was similar ( 25 of $2605[0.96 \%]$ for pioglitazone vs 22 of 2633 [0.84\%] for placebo; $P=0.639$ ) (Table 2). Among patients with a serious CHF event, subsequent all-cause mortality tended to be lower with pioglitazone (40 of 149 [26.8\%] vs 37 of 108 [34.3\%] with placebo; $P=0.1338$ ). Proportionately fewer pioglitazone patients with serious $\mathrm{CHF}$ went on to have an event in the primary $(47.7 \%$ with pioglitazone vs $57.4 \%$ with placebo; $P=0.0593)$ or main secondary 
endpoint (34.9\% with pioglitazone vs $47.2 \%$ with placebo; $P=0.025)$ [38]. In the subgroup of patients who had a previous MI, the rates of CHF requiring hospitalization were 7.5\% (92 of 1230 patients) with pioglitazone and $5.2 \%$ (63 of 1215$)$ with placebo. Again, fatal CHF rates were similar ( $1.4 \%$ with pioglitazone vs $0.9 \%$ with placebo) [34].

Independent clinical predictors for CHF events were identified by Cox regression in a post hoc analysis of the PROactive trial and were used for calculating a risk prediction score [39]. Overall, 233 of 4951 patients with available baseline data suffered a serious adverse CHF event during a mean follow-up of 34.5 months. Age, renal dysfunction, diuretic use, HbAlc, duration of diabetes, low-density lipoprotein (LDL)-cholesterol, heart rate, bundle branch block, microalbuminuria, previous MI and pioglitazone treatment were independent predictors of CHF. The score stratified well in subgroups defined by pioglitazone treatment, prior MI, obesity, poor glycaemic control and microalbuminuria.

Thus, although the incidence of serious CHF was increased with pioglitazone versus placebo in the total PROactive population of patients with T2DM and macrovascular disease, subsequent mortality or morbidity was not increased in PROactive patients with serious CHF. It is noteworthy that, in a similar analysis, the risk of $\mathrm{CHF}$ and associated deaths was specifically analysed in the RECORD trial with rosiglitazone. In the rosiglitazone group, the risk of CHF death or hospitalization was doubled versus metformin or sulfonylurea: HR $=2.10,95 \% \mathrm{CI}, 1.35-3.27$. An excess in CHF deaths was observed (10 vs 2), including four CHF deaths as first CHF events (Table 2) [40]. These data support a better safety profile of pioglitazone compared to rosiglitazone. In a meta-analysis of 94 clinical trials, the observed increase in incidence of non-fatal CHF with pioglitazone was not statistically significant when compared with placebo or an active comparator [odds ratio $=1.38,95 \% \mathrm{CI}$ $0.90-2.12$ ) [41]. Despite an increase in fluid-related events, recent studies suggested that individuals with T2DM and CHF (NYHA grade I/II) can be treated with pioglitazone with appropriate monitoring and adjustment of CHF therapies [42].

\subsection{Varia}

Baseline 12-lead electrocardiographs available in 5231 of the 5238 participants of the PROactive trial were analysed for heart rate, heart rate corrected QT (cQT)-interval, presence of atrial fibrillation/flutter, left axis deviation, right and left bundle branch block [43]. The association of electrocardiographic signs with total mortality, the principal secondary composite endpoint (death, MI and stroke) and serious adverse CHF events was examined by Cox-regression analysis. Overall, 223 (4.3\%) patients showed atrial fibrillation/flutter, 213 (4.1\%) patients had right bundle branch block, 111 (2.1\%) patients had left bundle branch block and 706 (13.5\%) patients had left axis deviation. In multivariate adjusted analyses, heart rate and cQT-interval were significantly associated with mortality, the composite secondary endpoint and CHF, whereas right and left bundle branch blocks were significantly associated with CHF only. Left axis deviation was associated with CHF and atrial fibrillation/flutter was associated with mortality and CHF in univariate but not multivariate analyses. Thus, easily assessable electrocardiographic signs such as heart rate, cQT-interval and bundle branch blocks were predictive for adverse outcome independently of multiple risk factor adjustment and should be considered in clinical care.

Finally, a post hoc analysis of the PROactive study investigated the incidence of new onset ECG abnormalities in patients with T2DM and macrovascular disease [44]. The cumulative incidence during the mean trial followup of 34.5 months based on all available post-baseline ECGs was $2.5 \%$ for atrial fibrillation, $1.5 \%$ for right bundle branch block, $1.0 \%$ for left bundle branch block and $2.4 \%$ for left axis deviation. Given the strong prognostic impact of these ECG abnormalities (see above) and substantial therapeutic consequences, these findings highlight the need to regularly assess ECG in this patient population to detect individuals at high risk of CV events.

\section{Other clinical outcomes}

\subsection{Cancer}

A meta-analysis of data from large randomized controlled trials of intensified glycaemic control (PROactive plus UKPDS, ACCORD, VADT) suggested that cancer risk is not reduced by improving glycaemic control in T2DM [45]. In the whole cohort of PROactive, the comparative incidence of all malignancies was similar; however, more cases of bladder neoplasm (14 vs 5) and fewer cases of breast cancer (3 vs 11) were observed in the pioglitazone versus placebo arms of the study [10]. PROactive was the first trial that raised the question of a possible increase in bladder cancer risk with pioglitazone $(\mathrm{RR}=2.36,95 \% \mathrm{CI} 0.91-6.13)$. 
In a recent meta-analysis of five studies (including PROactive), pioglitazone was associated with a significantly higher risk of bladder cancer $(\mathrm{RR}=1.17,95 \% \mathrm{CI} 1.03-1.32, P=0.013)$ [46]. No relation between pioglitazone and bladder cancer was found for duration of therapy $<12$ months and cumulative dose $<28,000 \mathrm{mg}$. The RR for bladder cancer in subjects with 12-24months of pioglitazone use was $1.34(95 \%$ CI 1.08-1.66, $P=0.008)$. The effect was even stronger for cumulative treatment duration $>24$ months (RR 1.38, 95\% CI 1.12-1.70, $P=0.003$ ). There was a significant risk for patients with cumulative dose $>28,000 \mathrm{mg}$ (RR $1.58,95 \% \mathrm{CI} 1.12-2.06, P=$ 0.001 ). In a retrospective cohort study using a nested case-control analysis, ever use of pioglitazone was associated with an increased rate of bladder cancer $(\mathrm{RR}=1.83,95 \% \mathrm{CI} 1.10-3.05)$. Again, the rate increased as a function of duration of use, with the highest rate observed in patients exposed for more than 24 months $(R R=$ $1.99,1.14-3.45)$ and in those with a cumulative dosage greater than $28000 \mathrm{mg}(\mathrm{RR}=2.54,1.05-6.14)$ [47].

\subsection{Bone fractures}

In PROactive, a higher rate of bone fractures was observed among pioglitazone-treated female patients $(5.1 \%$ vs $2.5 \%$ ) [27]. A meta-analysis of data from 10 randomized controlled trials (including PROactive) and from 2 observational studies confirmed that long-term TZD use doubles the risk of fractures among women with T2DM, without a significant increase among men [48]. These data were confirmed in a case-control study [49]. Postmenopausal women taking TZDs and the subset of men taking both loop diuretics and TZDs were at increased risk for fractures. In postmenopausal women, risk was associated with higher TZD dose. No difference between rosiglitazone and pioglitazone was apparent.

\subsection{Oedema and weight gain}

As in previous studies, pioglitazone was associated with typical, but manageable, increases in oedema $(26.4 \% \mathrm{vs}$ $15.1 \%$ for placebo) and weight gain (mean change of $+3.8 \mathrm{~kg}$ vs $-0.6 \mathrm{~kg}$ for placebo) in the PROactive cohort [27].

A post hoc analysis of body weight and weight change in relation to outcome has been performed [50]. The lowest mortality was seen in patients with body mass index (BMI) $30-35 \mathrm{~kg} / \mathrm{m}^{2}$ at baseline. In comparison to this (reference group), patients in the placebo group with BMI $<22 \mathrm{~kg} / \mathrm{m}^{2}(\mathrm{HR}=2.96,95 \%$ CI $1.27-6.86, P=0.012)$ and BMI 22 to $25 \mathrm{~kg} / \mathrm{m}^{2}(\mathrm{HR}=1.88,95 \%$ CI 1.11-3.21, $P=0.019)$ had a higher all-cause mortality. Weight loss during the PROactive study was associated with increased total mortality (HR per 1\% body weight: 1.13, 95\% CI 1.11-1.16, $P<0.0001$ ), with increased CV mortality, all-cause hospitalization and the composite of death, MI and stroke. In contrast, weight gain was not associated with increased mortality. Weight gain in patients treated with pioglitazone (mean $+4.0 \pm 6.1 \mathrm{~kg}$ ) predicted a better prognosis (HR per $1 \%$ weight gain: $0.96,95 \%$ CI $0.92-$ $1.00, P=0.037$ ) compared to patients without weight gain. Surprising, among patients with T2DM and CV comorbidity in PROactive, overweight and obese patients had a lower mortality compared to patients with normal weight. Weight loss but not weight gain was associated with increased mortality and morbidity. There may be an "obesity paradox" in patients with T2DM and CV risk.

\subsection{Kidney function}

Background and human studies have shown that TZDs reduce urinary albumin and protein excretion and interfere with most of the pathogenentic pathways involved in the development and progression of diabetic nephropathy [51]. In PROactive, creatinine values remained constant in both groups throughout the study. Changes in microalbuminuria were similar in the two groups [10].

Patients with diabetes and chronic kidney disease (CKD) are at particularly high risk for CV disease. A post hoc analysis from PROactive investigated the relationship between CKD and incident CV outcomes in a population of patients with T2DM and documented macrovascular disease, as well as the effects of pioglitazone treatment on recurrent $\mathrm{CV}$ disease [52]. CKD, defined as an estimated glomerular filtration rate $(\mathrm{GFR})<60 \mathrm{ml} / \mathrm{min}$ per $1.73 \mathrm{~m}^{2}$, was present in $597(11.6 \%)$ of 5154 patients of PROactive. More patients with CKD reached the primary composite endpoint than patients without CKD $(27.5 \%$ vs $19.6 \% ; P<0.0001)$. Patients with CKD were also more likely to reach the main secondary composite endpoint (all-cause mortality, MI, and stroke). Patients who had CKD and were treated with pioglitazone were less likely to reach this secondary endpoint $(\mathrm{HR}=0.66$, 95\% CI 0.45-0.98), but this association was not observed among those with better renal function (Table 1). However, and surprisingly, there was a greater decline in estimated GFR with pioglitazone (between-group difference $0.8 \mathrm{ml} / \mathrm{min}$ per $1.73 \mathrm{~m}^{2} /$ year) than with placebo. Thus, PROactive confirmed that CKD is an independent risk factor for $\mathrm{CV}$ events and death among patients with diabetes and preexisting macrovascular disease. Patients who had CKD and were treated with pioglitazone were less likely to reach a composite 
endpoint of all-cause death, MI, and stroke, independent of the severity of renal impairment. Nevertheless, according to a recent meta-analysis of clinical trials, whether the use of TZDs has a positive or a negative impact upon major $\mathrm{CV}$ and renal outcomes in diabetic patients remains an open, unanswered question [53].

\section{Metabolic outcomes}

\subsection{Glucose control}

Overall, the addition of pioglitazone uptitrated to $45 \mathrm{mg}$ /day resulted in a $0.5 \%$ reduction in HbA1c (Table 3 ) [10]. As the diabetic population in PROactive was rather heterogeneous regarding glucose-lowering modalities at randomization, several post hoc analyses were performed to more specifically analyse the metabolic effects of pioglitazone in various subgroups separated according to baseline therapy. Intensifying an existing oral monotherapy regimen (metformin: $n=514$; sulfonylurea: $n=1001$ ) to a dual oral regimen by adding pioglitazone versus placebo resulted in sustained improvements in glycaemic control and reduced progression to insulin therapy [54]. In patients treated with metformin plus sulfonylurea combination therapy and not receiving insulin at baseline $(n=1314)$, significantly greater reductions in HbA1c and greater proportions of patients with $\mathrm{HbA1c}$ at target were noted with pioglitazone versus placebo, despite a decrease in the use of other oral glucoselowering agents. There was an approximate twofold increase in progression to permanent insulin use in the placebo group vs the pioglitazone group when added to combination therapy. The overall safety of the metformin-sulfonylurea-pioglitazone triple therapy was good [55]. Almost one third of the total population were receiving insulin at baseline. A rapid and sustained decrease in insulin dose was observed with pioglitazone versus a progressive increase with placebo. By study end, the mean insulin dose was lower with pioglitazone (42 $\mathrm{U} /$ day vs $55 \mathrm{U} /$ day with placebo, $P<0.0001)$. Nevertheless, a greater HbA1c reduction was observed with pioglitazone (Table 3). Thus, pioglitazone use in combination with insulin resulted in a sustained improved glycaemic control and allowed the treatment regimens to be simplified and the insulin doses reduced [56]. PROactive also confirmed that the combination insulin plus pioglitazone is well tolerated, an important piece of information because concern was raised previously regarding the safety of such a combination [57].

In conclusion, post hoc analyses of PROactive demonstrate that the addition of pioglitazone titrated up to $45 \mathrm{mg}$ significantly reduces $\mathrm{HbA} 1 \mathrm{c}$ levels by about $0.5 \%$ whatever baseline glucose lowering therapy, metformin alone, sulfonylurea alone, metformin-sulfonylurea combination or insulin (with or without oral agents). These favourable metabolic effects were sustained up to 2.8 years (Table 3 ).

Table 3 - Impact of pioglitazone on glucose control in the various subgroups of PROactive. Results are expressed as mean $\pm S D$ or as number of patients (\%). Differences between pioglitazone and placebo: all $P<$ 0.001. NA, not available.

\begin{tabular}{|c|c|c|c|}
\hline $\begin{array}{l}\text { Patients subgroups according to } \\
\text { baseline therapy }\end{array}$ & $\begin{array}{l}\text { HbAlc reduction } \\
\quad(\text { mean, } \%)\end{array}$ & $\begin{array}{c}\text { HbAlc }<7 \% \\
(53 \mathrm{mmol} / \mathrm{mol}) \\
n(\% \text { patients })\end{array}$ & $\begin{array}{l}\text { Permanent use of insulin } \\
n \text { ( } \% \text { patients })\end{array}$ \\
\hline \multicolumn{4}{|l|}{ All treatments [10] } \\
\hline Pioglitazone $(n=2605)$ & $-0.8(-1.6 \text { to }-0.1)^{\mathrm{a}}$ & NA & $183 / 1741^{\mathrm{b}}(11)$ \\
\hline Placebo $(n=2633)$ & $-0.3(-1.1 \text { to } 0.4)^{\mathrm{a}}$ & NA & $362 / 1737^{\mathrm{b}}(21)$ \\
\hline \multicolumn{4}{|l|}{ Metformin only [54] } \\
\hline Pioglitazone $(n=253)$ & $-0.8 \pm 1.2$ & $156(68.1)$ & $8(3.4)$ \\
\hline Placebo $(n=261)$ & $-0.3 \pm 1.5$ & $108(46.8)$ & $16(6.5)$ \\
\hline \multicolumn{4}{|l|}{ Sulfonylurea only [54] } \\
\hline Pioglitazone $(n=508)$ & $-0.9 \pm 1.3$ & $287(64.1)$ & $30(6.3)$ \\
\hline Placebo $(n=493)$ & $-0.4 \pm 1.3$ & $166(38.9)$ & $67(14.8)$ \\
\hline \multicolumn{4}{|l|}{ Metformin + sulfonylurea [55] } \\
\hline Pioglitazone $(n=654)$ & $-0.9 \pm 1.3$ & $269(46.4)$ & $95(15.5)$ \\
\hline Placebo $(n=660)$ & $-0.3 \pm 1.4$ & $152(26.5)$ & $190(31.1)$ \\
\hline \multicolumn{4}{|l|}{ Insulin $[56]$} \\
\hline Pioglitazone $(n=864)$ & $-0.93 \pm \mathrm{NA}$ & $308(41.7)$ & $790(81.4)$ \\
\hline Placebo $(n=896)$ & $-0.45 \pm \mathrm{NA}$ & $188(24.3)$ & $881(98.3)$ \\
\hline
\end{tabular}

a $95 \%$ confidence interval

${ }^{\mathrm{b}}$ In patients not receiving insulin at randomization. 


\subsection{Lipid profile}

As previously discussed [26], subgroup analyses by baseline statin use in PROactive suggested that the benefit of pioglitazone on the composite of all-cause mortality, nonfatal MI, or stroke (main secondary endpoint in PROactive) was observed in patients not receiving a statin at baseline ( $\mathrm{HR}=0.77,95 \% \mathrm{CI} 0.64-0.93, P=0.008)$, but was not evident in those receiving statins at baseline ( $\mathrm{HR}=0.97,95 \% \mathrm{CI} 0.75-1.26, \mathrm{P}=0.845)$ [26]. However, the interaction between baseline statin use and the effect of pioglitazone did not reach statistical significance for this endpoint $(P=0.1547)$, indicating that the effect of pioglitazone, relative to placebo, was similar regardless of baseline statin use or not [26].

In PROactive, as in CHICAGO and PERISCOPE, there was a sustained effect of pioglitazone on glycaemic control and, in addition, beneficial effects in reducing triglycerides and increasing high-density lipoprotein cholesterol (HDL)-cholesterol beyond that seen with concomitant statin therapy [33].

A post hoc study examined the effect of pioglitazone on triglycerides, HDL-cholesterol, and LDL-cholesterol levels in patients from PROactive to determine whether pioglitazone-induced lipid effects were altered by different baseline antihyperglycaemia medication or statin use [58]. Independent ofglucose-lowering agent and statin use, triglyceride levels decreased in all subgroups treated with pioglitazone (-9.9\% to $-12.3 \%)$, whereas little change was observed in placebo groups. HDL-cholesterol increased nearly twice as much with pioglitazone (18.1-20.3\%) as with placebo (8.1-11.8\%) across all subgroups. LDL-cholesterol increased moderately with pioglitazone (5.2-9.6\%) compared with placebo (3.3-7.6\%). Thus, long-term pioglitazone therapy led to durable improvements in triglyceride and HDL-cholesterol levels, irrespective of baseline antihyperglycaemia therapy or statin use.

Because pioglitazone improved both glucose control and lipid profile in PROactive, an interesting question is to know which of the metabolic changes can best explain the reduction in CV events. Although pioglitazone treatment was associated with a decrease in $\mathrm{HbAlc}$ and an increase in HDL-cholesterol, only the change from baseline HDL-cholesterol predicted the CV outcome $\left(\chi^{2}=28.89, P<0.0001\right)$. No other variables, including $\mathrm{HbA1c}$, triglycerides and systolic blood pressure, showed significant direct associations with CV outcome [59]. Pioglitazone and rosiglitazone have significantly different effects on plasma lipids independent of glycaemic control or concomitant lipid-lowering or other antihyperglycaemic therapy. Pioglitazone compared with rosiglitazone is associated with significant improvements in triglycerides, HDL-cholesterol, LDL particle concentration, and LDL particle size $[60,61]$. Such difference in lipid effects may at least partially explain the different $\mathrm{CV}$ risk profile between pioglitazone and rosiglitazone [15,62-66].

\section{Pharmacoeconomic evaluation}

The publication of PROactive provides a relevant platform upon which to base a detailed economic evaluation of the possible additional benefit of pioglitazone over and above current best treatment in patients with T2DM and severe CV disease. Pioglitazone improved CV outcome and reduced the need to add insulin to existing therapy, which may contribute to reduce further expenses [67].

The cost-effectiveness of adding pioglitazone to existing treatment regimens in patients with T2DM with a history of macrovascular disease who are at high risk of further CV events has been analysed for different countries: United Kingdom [68], United States of America [69], Switzerland [70] and Germany [71,72]. The incremental cost-effectiveness ratio (ICER) per quality-adjusted life expectancy (QALY) gained with pioglitazone vs placebo was pounds 4060 in UK [68], \$44,105 in the US [69], CHF 60,596 in Switzerland [70], and $€ 13,294$ in Germany [71,72]. The addition of pioglitazone to existing therapy in patients with T2DM at high risk of further $\mathrm{CV}$ events was considered cost-effective and may represent good value for money by currently accepted standards in these countries. It is noteworthy that the loss of patent of pioglitazone, which is now genericable, will substantially reduce the cost of the drug and thereby reduce the ICER, thus further improving the cost-effectiveness of such therapy with a TZD in the future.

\section{Lessons for the clinician and perspectives}

TZDs initially showed great promise as unique PPAR-gamma receptor-mediated oral therapy for T2DM and acting specific insulin sensitizers [2], but a host of serious side effects, primarily CV events for rosiglitazone [21], have limited their utility. Although TZDs are traditionally classed according to their target, they have different and sometimes conflicting clinical benefit and adverse event profiles. It is speculated that this is because of differing properties and specificities for the PPAR receptors (each of which targets specific genes) 
[73]. This is most obvious in the different impact on CV outcomes between pioglitazone and rosiglitazone in prospective clinical trials (less MI in PROactive versus a trend for more MI in RECORD, for instance). A metaanalysis of 16 observational studies that directly compared the risk of $\mathrm{CV}$ outcomes for rosiglitazone and pioglitazone among patients with T2DM, including 810,000 TZDs users, showed that rosiglitazone is associated with significantly higher odds of CHF, MI, and death relative to pioglitazone in real world settings [23]. However, pioglitazone may also be associated with several adverse events, including body weight gain, fluid retention, $\mathrm{CHF}$, peripheral bone fractures (especially in women) and possibly bladder cancer. All these adverse events were detected in PROactive [27], and confirmed in real life [28,64]. Therefore, it is crucial to perform a risk-benefit analysis to determine what role pioglitazone should play in our current treatment of T2DM [28].

An important question is whether the results from the controlled trial PROactive may be transposed into clinical practice in real life. In other words, should we be "proactive" in prescribing TZDs [74] and what does PROactive mean for primary care physicians? [75] In an increasing competitive environment among glucose-lowering therapies, the place of pioglitazone, as monotherapy, dual therapy or triple therapy, in the management of T2DM has been nicely summarized in the recent ADA-EASD position statement [29].

\section{Conclusion}

Although severely criticized by some researchers or clinicians, PROactive is a landmark study that contains a lot of information of potential interest. The main criticism concerns a too heterogeneous composite primary endpoint, which combined both disease-driven and revascularization procedural endpoints, and endpoints such as foot amputation which maybe driven by confounding factors such as infection. Furthermore, because the final analysis of the trial was event-driven and because of the numerous various events included in the primary endpoint, the consequence was a probably too short duration of the study to draw clear-cut and definite conclusions about CV outcomes. Nevertheless, all post hoc secondary analyses that have been perfomed since the original publication of PROactive in 2005 confirmed the value of pioglitazone as a glucose-lowering agent (as oral monotherapy, dual therapy, triple therapy and even combination with insulin), with additive positive effects that may contribute to coronary and cerebrovascular protection. However, even if pioglitazone exerts cardioprotective action and has proven to be cost-effective in patients with T2DM and macrovascular disease, its clinical use may be limited by the occurrence of several adverse events. Thus, the clinician should balance the pro and contra of using pioglitazone considering the individual patient's characteristics (patient-centred strategy as recommended by the recent ADA-EASD position statement).

\section{Funding}

No sources of funding were used to assist in the preparation of this manuscript.

\section{Conflict of interest}

The author declares that he has no conflict of interest. A.J. Scheen was an investigator of the PROactive trial and member of the International Steering Committee.

A.J. Scheen has received lecture/advisor fees from Astra-Zeneca/BMS, Boehringer Ingelheim, Eli Lilly, GlaxoSmithKline, Merck Sharp \& Dohme, Novartis, NovoNordisk, Sanofi-Aventis and Servier.

\section{REFERENCES}

[1] Mazzone T, Chait A, Plutzky J. Cardiovascular disease risk in type 2 diabetes mellitus: insights from mechanistic studies. Lancet 2008;371:1800-9.

[2] Yki-Jarvinen H. Thiazolidinediones. N Engl J Med 2004;351:1106-18.

[3] Chan JYC, Ilag L, Tan MH. Effects of thiazolidinediones on the triad of type 2 diabetes mellitus, insulin resistance and cardiovascular disease. Diabetes Res Clin Pract 2007;78:S3-13.

[4] Derosa G. Efficacy and tolerability of pioglitazone in patients with type 2 diabetes mellitus: comparison with other oral antihyperglycaemic agents. Drugs 2010;70:1945-51.

[5] de Pablos-Velasco P. Pioglitazone: beyond glucose control. Expert Rev Cardiovasc Ther 2010;8:1057-67.

[6] Barnett AH. Redefining the role of thiazolidinediones in the management of type 2 diabetes. Vasc Health Risk Manage 2009;5:141-51. 
Published in : Diabetes Research \& Clinical Practice (2012)

Status : Postprint (Author's version)

[7] Campbell IW. Pioglitazone - An oral antidiabetic agent and metabolic syndrome F modulator. Can theory translate into practice? Br J Diabetes Vasc Dis 2005;5:209-16.

[8] Pfützner A, Schneider CA, Forst T. Pioglitazone: an

antidiabetic drug with cardiovascular therapeutic effects. Expert Rev Cardiovasc Ther 2006;4:445-59.

[9] Charbonnel B, Dormandy J, Erdmann E, Massi-Benedetti M, Skene A, PROactive Study Group. The prospective pioglitazone clinical trial in macrovascular events (PROactive): can pioglitazone reduce cardiovascular events in diabetes? Study design and baseline characteristics of 5238 patients. Diabetes Care 2004;27:1647-53.

[10] Dormandy JA, Charbonnel B, Eckland DJ, Erdmann E, Massi-Benedetti M, Moules IK, et al. Secondary prevention of macrovascular events in patients with type 2 diabetes in the PROactive Study (PROspective pioglitAzone Clinical Trial In macroVascular Events): a randomised controlled trial. Lancet 2005;366:1279-89.

[11] Yki-Jarvinen H. The PROactive study: some answers, many questions. Lancet 2005;366:1241-2.

[12] Fonseca V, Jawa A, Asnani S, Commentary:. The PROactive study - the glass is half full. J Clin Endocrinol Metab 2006;91:25-7.

[13] Rizza R, Henry R, Kahn R. Commentary on the results and clinical implications of the PROactive study. Diabetes Care 2005;28:2965-7.

[14] Skyler JS, PROactive:. A sad tale of inappropriate analysis and unjustified interpretation. Clin Diabetes 2006;24:63-5.

[15] Erdmann E, Charbonnel B, Wilcox R. Thiazolidinediones and cardiovascular risk - a question of balance. Curr Cardiol Rev 2009;5:15565

[16] Erdmann E, Dormandy J, Wilcox R, Massi-Benedetti M, Charbonnel B. PROactive 07: pioglitazone in the treatment of type 2 diabetes: results of the PROactive study. Vasc Health Risk Manage 2007;3:355-70.

[17] Khanderia U, Pop-Busui R, Eagle KA. Thiazolidinediones in type 2 diabetes: a cardiology perspective. Ann Pharmacother 2008;42:1466-74.

[18] Krentz A, Thiazolidinediones:. effects on the development and progression of type 2 diabetes and associated vascular complications. Diabetes Metab Res Rev 2009;25:112-26.

[19] Ryder REJ, Pioglitazone:. An agent which reduces stroke, myocardial infarction and death and is also a key component of the modern paradigm for the optimum management of type 2 diabetes. Br J Diabetes Vasc Dis 2011;11:113-20.

[20] Richter B, Bandeira-Echtler E, Bergerhoff K, Clar C, Ebrahim SH. Pioglitazone for type 2 diabetes mellitus. Cochrane Database Syst Rev 2006. http://dx.doi.org/10.1002/ 14651858.CD006060.pub2. CD006060

[21] Nissen SE, Wolski K. Effect of rosiglitazone on the risk of myocardial infarction and death from cardiovascular causes. N Engl J Med 2007;356:2457-71.

[22] Home PD, Pocock SJ, Beck-Nielsen H, Curtis PS, Gomis R, Hanefeld M, et al. Rosiglitazone evaluated for cardiovascular outcomes in oral agent combination therapy for type 2 diabetes (RECORD): a multicentre, randomised, open-label trial. Lancet 2009;373:2125-35.

[23] Loke YK, Kwok CS, Singh S. Comparative cardiovascular effects of thiazolidinediones: systematic review and metaanalysis of observational studies. Br Med J 2011;342:d1309.

[24] Nathan DM, Buse JB, Davidson MB, Ferrannini E, Holman RR, Sherwin R, et al. Medical management of hyperglycaemia in type 2 diabetes mellitus: a consensus algorithm for the initiation and adjustment of therapy: a consensus statement from the American Diabetes Association and the European Association for the Study of Diabetes. Diabetologia 2009;52:17-30.

[25] Pouwels KB, van Grootheest K. The rosiglitazone decision process at FDA and EMA. What should we learn? Int J Risk Saf Med $2012 ; 24: 73-80$

[26] Betteridge DJ, DeFronzo RA, Chilton RJ. PROactive: time for a critical appraisal. Eur Heart J 2008;29:969-83.

[27] Dormandy J, Bhattacharya M, Van Troostenburg De Bruyn AR. Safety and tolerability of pioglitazone in high-risk patients with type 2 diabetes: an overview of data from PROactive. Drug Saf 2009;32:187-202.

[28] Kung J, Henry RR. Thiazolidinedione safety. Expert Opin Drug Saf 2012;11:565-79.

[29] Inzucchi SE, Bergenstal RM, Buse JB, Diamant M, Ferrannini E, Nauck M, et al. Management of hyperglycaemia in type 2 diabetes: a patient-centered approach. Position statement of the American Diabetes Association (ADA) and the European Association for the Study of Diabetes (EASD). Diabetologia 2012;55:1577-96. 
[30] Erdmann E, Spanheimer R, Charbonnel B, Investigators PS. Pioglitazone and the risk of cardiovascular events in patients with Type 2 diabetes receiving concomitant treatment with nitrates, renin-angiotensin system blockers, or insulin: results from the PROactive study (PROactive 20). J Diabetes 2010;2:212-20.

[31] Lincoff AM, Wolski K, Nicholls SJ, Nissen SE. Pioglitazone and risk of cardiovascular events in patients with type 2 diabetes mellitus: a meta-analysis of randomized trials. J Am Med Assoc 2007;298:1180-8.

[32] Wilcox R, Kupfer S, Erdmann E, PROactive Study investigators. Effects of pioglitazone on major adverse cardiovascular events in high-risk patients with type 2 diabetes: results from PROspective pioglitAzone Clinical Trial In macro Vascular Events (PROactive 10). Am Heart J 2008; 155:712-7.

[33] Betteridge DJ. CHICAGO, PERISCOPE and PROactive: CV risk modification in diabetes with pioglitazone. Fundam Clin Pharmacol 2009;23:675-9.

[34] Erdmann E, Dormandy JA, Charbonnel B, Massi-Benedetti M, Moules IK, Skene AM, et al. The effect of pioglitazone on recurrent myocardial infarction in 2445 patients with type 2 diabetes and previous myocardial infarction: results from the PROactive (PROactive 05) study. J Am Coll Cardiol 2007;49:1772-80.

[35] Wilcox R, Bousser MG, Betteridge DJ, Schernthaner G, Pirags V, Kupfer S, et al. Effects of pioglitazone in patients with type 2 diabetes with or without previous stroke: results from PROactive (PROspective pioglitAzone Clinical Trial In macroVascular Events 04). Stroke 2007;38:865-73

[36] Dormandy JA, Betteridge DJ, Schernthaner G, Pirags V, Norgren L, PROactive investigators. Impact of peripheral arterial disease in patients with diabetes - results from PROactive (PROactive 11). Atherosclerosis 2009;202: 272-81.

[37] Rydén L, Thráinsdóttir I, Swedberg K. Adjudication of serious heart failure in patients from PROactive. Lancet 2007;369:189-90.

[38] Erdmann E, Charbonnel B, Wilcox RG, Skene AM, Massi-Benedetti M, Yates J, et al. Pioglitazone use and heart failure in patients with type 2 diabetes and preexisting cardiovascular disease: data from the PROactive study (PROactive 08). Diabetes Care 2007;30:2773-8.

[39] Pfister R, Cairns R, Erdmann E, Schneider CA. A clinical risk score for heart failure in patients with type 2 diabetes and macrovascular disease: an analysis of the PROactive study. Int J Cardiol 2011. http://dx.doi.org/10.1016/ j.ijcard.2011.05.056. Pii: S0167-5273(11)00469-4 [Epub ahead of print]

[40] Komajda M, McMurray JJ, Beck-Nielsen H, Gomis R, Hanefeld M, Pocock SJ, et al. Heart failure events with rosiglitazone in type 2 diabetes: data from the RECORD clinical trial. Eur Heart J 2010;31:824-31.

[41] Mannucci E, Monami M, Lamanna C, Gensini GF, Marchionni N. Pioglitazone and cardiovascular risk. A comprehensive meta-analysis of randomized clinical trials. Diabetes Obes Metab 2008;10:1221-38.

[42] Macfarlane DP, Fisher M. Thiazolidinediones in patients with diabetes mellitus and heart failure: implications of emerging data. Am J Cardiovasc Drugs 2006;6:297-304.

[43] Pfister R, Cairns R, Erdmann E, Schneider CA. Prognostic impact of electrocardiographic signs in patients with type 2 diabetes and cardiovascular disease: results from the PROactive study. Diabet Med 2011;28:1206-12.

[44] Pfister R, Michels G, Cairns R, Schneider CA, Erdmann E. Incidence of new onset bundle branch block and atrial fibrillation in patients with type 2 diabetes and macrovascular disease: an analysis of the PROactive study. Int J Cardiol 2011;153:233-4.

[45] Johnson JA, Bowker SL. Intensive glycaemic control and cancer risk in type 2 diabetes: a meta-analysis of major trials. Diabetologia $2011 ; 54: 25-31$

[46] Zhu Z, Shen Z, Lu Y, Zhong S, Xu C. Increased risk of bladder cancer with pioglitazone therapy in patients with diabetes: a metaanalysis. Diabetes Res Clin Pract 2012. http://dx.doi.Org/10.1016/j.diabres.2012.05.006 [Epub ahead of print].

[47] Azoulay L, Yin H, Filion KB, Assayag J, Majdan A, Pollak MN, et al. The use of pioglitazone and the risk of bladder cancer in people with type 2 diabetes: nested case-control study. Br Med J 2012;344:e3645.

[48] Loke YK, Singh S, Furberg CD. Long-term use of thiazolidinediones and fractures in type 2 diabetes: a metaanalysis. Can Med Assoc J 2009;180:32-9.

[49] Bilik D, McEwen LN, Brown MB, Pomeroy NE, Kim C, Asao K, et al. Thiazolidinediones and fractures: evidence from translating research into action for diabetes. J Clin Endocrinol Metab 2010;95:4560-5.

[50] Doehner W, Erdmann E, Cairns R, Clark AL, Dormandy JA, Ferrannini E, et al. Inverse relation of body weight and weight change with mortality and morbidity in patients with type 2 diabetes and cardiovascular co-morbidity: an analysis of the PROactive study population. Int J Cardiol 2011. http://dx.doi.Org/10.1016/j.ijcard.2011.09.039. Pii: S0167-5273(11)01768-2 [Epub ahead of print].

[51] Sarafidis PA, Georgianos PI, Lasaridis AN. PPAR-gamma agonism for cardiovascular and renal protection. Cardiovasc Ther 
Published in : Diabetes Research \& Clinical Practice (2012)

Status : Postprint (Author's version)

$2011 ; 29: 377-84$

[52] Schneider CA, Ferrannini E, Defronzo R, Schernthaner G, Yates J, Erdmann E. Effect of pioglitazone on cardiovascular outcome in diabetes and chronic kidney disease. J Am Soc Nephrol 2008;19:182-7.

[53] Bolignano D, Zoccali C. Glitazones in chronic kidney disease: potential and concerns. Nutr Metab Cardiovasc Dis 2012;22:167-75.

[54] Scheen AJ, Tan MH, Betteridge DJ, Birkeland K, Schmitz O, Charbonnel B. Long-term glycaemic effects of pioglitazone compared with placebo as add-on treatment to metformin or sulphonylurea monotherapy in PROactive (PROactive 18). Diabet Med 2009;26:1242-9.

[55] Scheen AJ, Tan MH, Betteridge DJ, Birkeland K, Schmitz O, Charbonnel B, et al. Long-term glycaemic control with metforminsulphonylurea-pioglitazone triple therapy in PROactive (PROactive 17). Diabet Med 2009;26:1033-9.

[56] Charbonnel B, DeFronzo R, Davidson J, Schmitz O, Birkeland K, Pirags V, et al. Pioglitazone use in combination with insulin in the prospective pioglitazone clinical trial in macrovascular events study (PROactive19). J Clin Endocrinol Metab 2010;95:2163-71.

[57] Scheen AJ. Combined thiazolidinedione-insulin therapy: should we be concerned about safety? Drug Saf 2004;27:841-56.

[58] Spanheimer R, Betteridge DJ, Tan MH, Ferrannini E, Charbonnel B, PROactive investigators. Long-term lipid effects of pioglitazone by baseline anti-hyperglycemia medication therapy and statin use from the PROactive experience (PROactive 14). Am J Cardiol 2009;104:2349 .

[59] Ferrannini E, Betteridge DJ, Dormandy JA, Charbonnel B, Wilcox RG, Spanheimer R, et al. High-density lipoprotein-cholesterol and not HbA1c was directly related to cardiovascular outcome in PROactive. Diabetes Obes Metab 2011;13:759-64.

[60] Goldberg RB, Kendall DM, Deeg MA, Buse JB, Zagar AJ, Pinaire JA, et al. A comparison of lipid and glycemic effects of pioglitazone and rosiglitazone in patients with type 2 diabetes and dyslipidemia. Diabetes Care 2005;28:1547-54.

[61] Betteridge DJ. Effects of pioglitazone on lipid and lipoprotein metabolism. Diabetes Obes Metab 2007;9:640-7.

[62] Hanefeld M. The role of pioglitazone in modifying the atherogenic lipoprotein profile. Diabetes Obes Metab 2009;11:742-56.

[63] Derosa G. Pioglitazone is a valid alternative to rosiglitazone. Am J Cardiovasc Drugs 2011;11:357-62.

[64] Tolman KG. The safety of thiazolidinediones. Expert Opin Drug Saf 2011;10:419-28.

[65] Fisher M. Improving cardiovascular risk - applying evidence-based medicine to glucose-lowering therapy with thiazolidinediones in patients with type 2 diabetes. Int J Clin Pract 2009;63:1354-68.

[66] Simo R, Rodriguez A, Caveda E. Different effects of thiazolidinediones on cardiovascular risk in patients with type 2 diabetes mellitus: pioglitazone versus rosiglitazone. Curr Drug Saf 2010;5:234-44.

[67] Bottomley J, Palmer AJ, Williams R, Dormandy J, Massi-Benedetti M. PROactive 03: pioglitazone, type 2 diabetes and reducing macrovascular events - economic implications? Br J Diabetes Vasc Dis 2006;6:63-70.

[68] Valentine WJ, Bottomley JM, Palmer AJ, Brandle M, Foos V, Williams R, et al. PROactive 06: cost-effectiveness of pioglitazone in type 2 diabetes in the UK. Diabet Med 2007;24:982-1002.

[69] Valentine WJ, Tucker D, Palmer AJ, Minshall ME, Foos V, Silberman C, et al. Long-term cost-effectiveness of pioglitazone versus placebo in addition to existing diabetes treatment: a US analysis based on PROactive. Value Health 2009;12:1-9.

[70] Brandle M, Goodall G, Erny-Albrecht KM, Erdmann E, Valentine WF. Cost-effectiveness of pioglitazone in patients with type 2 diabetes and a history of macrovascular disease in a Swiss setting. Swiss Med Wkly 2009;139:173-84.

[71] Bierwirth R, Liebl A, Gschwend MH. Cost-effectiveness of pioglitazone in patients with type2 diabetes and a history of macrovascular disease in Germany. Med Klin 2010;5: 32-9.

[72] Scherbaum WA, Goodall G, Erny-Albrecht KM, Massi- Benedetti M, Erdmann E, Valentine WJ. Cost-effectiveness of pioglitazone in type 2 diabetes patients with a history of macrovascular disease: a German perspective. Cost Eff Resour Alloc 2009;7:9.

[73] Cariou B, Charbonnel B, Staels B. Thiazolidinediones and PPARgamma agonists: time for a reassessment. Trends Endocrinol Metab 2012;23:205-15.

[74] Williams R. Should we be PROactive in prescribing thiazolidinediones? Pharm Pract 2006;16:218-21.

[75] Singaram V, Pratley R. The PROactive trial (PROspective pioglitAzone Clinical Trial In macroVascular Events): what does it mean for primary care physicians? Diab Vasc Dis Res 2007;4:237-40. 